\title{
PENGARUH KOMPENSASI, KOMPETENSI DAN KOMITMEN ORGANISASI TERHADAP KINERJA KARYAWAN SEKRETARIAT JENDERAL DEWAN PIMPINAN PUSAT PARTAI GOLONGAN KARYA
}

\author{
Sugina $^{* 1)}$, Po Abas Sunarya ${ }^{2)}$, Isrial ${ }^{3)}$ \\ 1,2,3 Dosen Fakultas Ekonomi dan Bisnis Universitas Raharja \\ 1'sugina@raharja.info, ${ }^{2}$ abas@raharja.info, ${ }^{3}$ isrial@raharja.info
}

\begin{abstract}
Abstrak
Penelitian ini bertujuan menguji pengaruh kompensasi, kompetensi, dan komitmen perusahaan terhadap kinerja karyawan Sekretariat Jenderal Dewan Pimpinan Pusat Partai Golongan Karya. Populasi dalam penelitian ini adalah seluruh karyawan Sekretariat Jenderal Dewan Pimpinan Pusat Partai Golongan Karya. Metode yang digunakan dalam penelitian ini adalah metode deskriptif, analisis regresi linier sederhana, regresi linier berganda, uji instrumen penelitian, serta pengujian hipotesis (uji parsial dan uji simultan). Hasil penelitian menunjukkan bahwa secara parsial kompensasi berpengaruh signifikan terhadap kinerja karyawan berdasarkan Adjusted R Square adalah 0,512 atau $51,29 \%$ sisanya $48,8 \%$ dipengaruhi variabel lainnya yang tidak masuk dalam penelitin ini. Untuk variabel kompetensi berpengaruh signifikan terhadap kinerja karyawan berdasarkan Adjusted R Square adalah 0,725 atau 72,5\% sisanya 27,5\% dipengaruhi oleh variabel lainnya yang tidak masuk dalam penelitian ini. Sementar itu, variabel komitmen perusahaan berpengaruh terhadap kinerja karyawan berdasarkan Adjusted R Square adalah 0,631\% atau 53,1\% sisanya $36,9 \%$ dipengaruhi variabel lainnya yang tidak masuk dalam penelitin ini. Secara simultan, kompensasi, kompetensi, dan komitmen perusahaan berpengaruh secara signifikan terhadap kinerja karyawan berdasarkan Adjusted R Square adalah 0,729 atau $72 \%$, sisanya yang $28 \%$ dipengaruhi oleh variabel lainnya yang tidak masuk dalam penelitian ini.
\end{abstract}

Kata kunci: Kompensasi, Kompetensi, Komitmen Organisasi, Kinerja karyawan

\section{Abstract}

This study purpose is to examine the effect of compensation, competence, and company commitment on the performance of employees of the General Secretariat of the Golongan Karya Party Central Executive Board. The population in this study were all employees of the Secretariat General of the Central Leadership Council of the Golongan Karya Party. The method used in this research is descriptive method, simple linear regression analysis, multiple linear regression, research instrument test, and hypothesis testing (partial test and simultaneous test). The results showed that partial compensation has a significant effect on employee performance based on the Adjusted $R$ Square is 0.512 or 51, 29\% and the remaining 48.8\% is influenced by other variables not included in this research. For the competency variable has a significant effect on employee performance based on the Adjusted $R$ Square is 0.725 or $72.5 \%$, the remaining $27.5 \%$ is influenced by other variables not included in this study. Meanwhile, the variable company commitment has an effect on employee performance based on the Adjusted $R$ Square is $0.631 \%$ or $53.1 \%$, the remaining $36.9 \%$ is influenced by other variables not included in this research. Simultaneously, compensation, competence, and company commitment have a significant effect on employee performance based on the Adjusted $R$ Square is 0.729 or $72 \%$, the remaining $28 \%$ is influenced by other variables not included in this study.

Keywords: Compensation,Competence, Organizational Commitment, Employee Performance 


\section{Pendahuluan}

Partai Golongan Karya (Partai Golkar), sebelumnya bernama Golongan Karya (Golkar) dan Sekretariat Bersama Golongan Karya (Sekber Golkar), adalah sebuah partai politik di Indonesia. Partai GOLKAR bermula dengan berdirinya Sekber GOLKAR pada masa-masa akhir pemerintahan Presiden Soekarno, tepatnya pada tanggal 20 Oktober 1964 yang dimotori oleh Angkatan Darat untuk menandingi pengaruh Partai Komunis Indonesia dalam kehidupan politik. Dalam perkembangannya, Sekber GOLKAR berubah menjadi Golongan Karya yang menjadi salah satu organisasi peserta Pemilu di Indonesia. Sebagai organisasi partai Politik yang besar dan sudah mapan, Partai GOLKAR memiliki struktur organisasi yang sangat kuat dan lengkap dari tingkat Pusat, (DPP) Tingkat Provinsi, (DPD-I), Tingkat Kabupaten/Kota, (DPD-II), Tingkat Kecamatan (PK) dan Tingkat Desa/ Kelurahan (PD/PL) atau sebutan lainnya.

Dengan membawa Visi yaitu, Terwujudnya masyarakat Indonesia yang bersatu, berdaulat, maju, modern, damai.adil, makmur, beriman dan berakhlak mulia, berkesadaran hukum dan lingkungan, menguasai ilmu pengetahuan dan teknologi dan bermartabat dalam tata pergaulan dunia. Adapun Misi organisasi Partai Golkar antara lain a. Menegakkan, mengamankan dan mempertahankan Pancasila sebagai Dasar Negara dan ideologi bangsa demi memperkokoh Negara Kesatuan Republik Indonesia. b. Mewujudkan cita cita Proklamasi melalui pelaksanaan pembangunan nasional di segala bidang untuk merealisasikan masyarakat yang demokratis dan berdaulat, sejahtera, adil dan makmur menegakan supremasi hukum dan menghormati hak asasi manusia, serta terwujudnya ketertiban dan perdamaian dunia, c. Mewujudkan pemerintahan yang efektif dengan tata pemerintahan yang baik, bersih, berwibawa dan demokratis (Program Umum Hasil Munas VIII Partai Golkar 2009).

Dewan Pimpinan Pusat Partai Golongan Karya adalah badan pelaksana tertinggi partai yang bersifat kolektif.Dewan Pimpinan Pusat berwenang menentukan kebijakan tingkat nasional sesuai dengan Anggaran Dasar dan Anggaran Rumah Tangga Partai Golongan Karya. Tugas pokok Dewan Pimpinan Pusat Partai Golongan Karya adalah memperjuangkan terwujudnya cita cita bangsa dan tujuan nasional melalui peningkatan segala aspek kehidupan yang meliputi ideologi, politik, ekonomi, agama, sosial budaya, serta pertahanan dan keamanan nasional. Dalam menjalankan kegiatannya DPP Partai GOLKAR dibantu oleh unsur pendukung yaitu Sekretariat Jenderal Dewan Pimpinan Pusat Partai Golongan Karya yang dipimpin oleh Kepala Sekretariat (Direktur Eksekutif), Sekretariat Jenderal Dewan Pimpinan Pusat Partai Golongan Karya mempunyai tugas pokok membantu Sekretaris Jenderal (Sekjen) dalam melaksanakan koordinasi pelayanan administrasi umum hubungan kerja dibidang administrasi dengan sekretariat Partai Politik dan lembaga lainnya serta memberikan dukungan pelaksanaan operasional serta pembinaan staf administrasi pada Dewan Pimpinan Pusat Partai Golongan Karya (Keputusan DPP Partai GOLKAR Nomor KEP$\underline{66 / D P P / G O L K A R / V / 2010}$ ).

Sekretariat Jenderal Dewan Pimpinan Pusat Partai Golongan Karya terdiri dari Kepala Sekretariat, Divisi Urusan Dalam, Perlengkapan dan Keamanan. Divisi 
Tata Usaha, Ketenagaan dan Keuangan, serta Divisi Data dan Perencanaan, hubungan Masyarakat dan Persidangan. Untuk mencapai tugas pokok maka Sekretariat Jenderal Dewan Pimpinan Pusat Partai Golongan karya dituntut untuk menciptakan kinerja yang baik sesuai yang diharapkan oleh organisasi, Kinerja pegawai secara umum adalah sebuah perwujudan kerja yang dilakukan oleh karyawan yang biasanya digunakan sebagai dasar atau acuan penilaian terhadap karyawan didalam suatu organisasi. Kinerja yang baik merupakan suatu langkah untuk menuju tercapainya tujuan organisasi oleh karena itu, kinerja juga merupakan sarana penentu dalam mencapai tujuan organisasi sehingga perlu diupayakan untuk meningkatkan kinerja karyawan.

Tabel 1. Data Karyawan Setjen DPP Partai Golkar Berdasarkan Jenjang Pendidikan formal dan informal

\begin{tabular}{ccccc}
\hline No & Jenjang Pendidikan & Pria & Perempuan & \% \\
\hline 1 & SD & 8 & 0 & 6,7 \\
2 & SMP & 9 & 2 & 9,2 \\
3 & SMA & 43 & 12 & 45,8 \\
4 & D3 & 12 & 6 & 15 \\
5 & S1 & 15 & 11 & 21,7 \\
6 & S2 & 2 & 0 & 1,6 \\
7 & S3 & 0 & 0 & 0 \\
8 & Diklat \& Kursus & 89 & 31 & 0 \\
& Keterampilan Jumlah & & & \\
& Karyawan 120 orang & & & $100 \%$
\end{tabular}

Sumber : Sekretariat DPP Partai Golkar

Berdasarkan data yang ada maka Penulis mengelompokan menjadi 2 (dua) Klaster berdasarkan jenjang pendidikan. . Klaster A adalah kelompok yang berpendidikan SD, SMP SLTA atau disebut klaster berpendidikan rendah dan Klaster B adalah kelompok yang berpendidikan D3, S1, S2 dan S3 atau disebut klaster berpendidikan tinggi, maka dengan klaster tersebut dapat diartikan bahwa sebagian besar karyawan sekretariat jenderal DPP Partai Golkar berpendidikan rendah sebesar $(62 \%)$ dan yang berpendidikan tinggi sebesar 38\%. Selain pendidikan formal, peneliti memperoleh informasi bahwa secara kelembagaan karyawan tidak pernah mendapatkan pembinaan yang bersifat pendidikan dan pelatihan atau kursus keterampilan lainnya, sehingga dari kemampuan kompetensi kurang optimal, dalam upaya meningkatkan kinerjanya.

Faktor lain yang juga tidak kalah pentingnya di dalam upaya peningkatan kinerja adalah faktor Komitmen organisasi. Komitmen organisasi merupakan tingkat sampai mana seorang karyawan memihak sebuah organisasi serta tujuan-tujuan dan keinginannya untuk mempertahankan keanggotaan dalam organisasi tersebut (Robbins 2008:100). Dikarenakan komitmen organisasional bersifat multidimensi, maka terdapat perkembangan dukungan untuk tiga model komponen yang diajukan oleh Mayer dan Allen. Ketiga dimensi tersebut adalah: 1. Komitmen afektif (affective commitment) adalah keterikatan emosional karyawan, 
identifikasi, dan keterlibatan dalam organisasi. 2. Komitmen keberlanjutan (continuance commitment) adalah komitmen berdasarkan kerugian yang berhubungan dengan keluarnya karyawan dari organisasi. Hal ini mungkin karena kehilangan senioritas atas promosi atau benefit. 3. Komitmen normatif (normative commitment) adalah perasaan wajib untuk tetap berada dalam organisasi karena memang harus begitu; tindakan tersebut merupakan hal benar yang harus dilakukan (Kreitner,2014:249).

Tabel 2. Data Kehadiran Karyawan Setjen DPP Partai Golkar selama Bulan MeiAgustus 2016 sebagai gambaran Variabel Komitmen organisasi

\begin{tabular}{cccccl}
\hline No & Bulan & $\begin{array}{c}\text { Jumlah Hari } \\
\text { Kerja \& Jumlah } \\
\text { Karyawan }\end{array}$ & $\begin{array}{c}\text { Jumlah } \\
\text { Hari } \\
\text { Kerja }\end{array}$ & $\begin{array}{c}\text { Jumlah } \\
\text { Kehadiran }\end{array}$ & $\begin{array}{c}\text { Jumlah } \\
\text { Ketiak } \\
\text { hairan }\end{array}$ \\
\hline 1 & Mei 2016 & 20 X 120 & 2.400 & $2.088(87 \%)$ & $312(13 \%)$ \\
2 & Juni 2016 & 22 X 120 & 2.640 & $2.127(80,6 \%)$ & $512(19.4 \%)$ \\
3 & Juli 2016 & 16 X 120 & 1.920 & $1.184(61,7 \%)$ & $736(38.3 \%)$ \\
4 & Aug 2016 & 23 X 120 & 2.760 & $2.229(80,7 \%)$ & $531(19.2 \%)$ \\
& & 81 x 120 & 9.720 & $7628(78,5 \%)$ & $2092(21,5 \%)$ \\
\hline
\end{tabular}

Sumber : Sekretariat DPP Partai Golkar

Dari data tabel diatas dapat diartikan bahwa kehadiran karyawan selama 4 bulan terakhir ini belum optimal hanya mencapai $78,5 \%$ dan selebihnya tidak hadir atau tidak masuk kerja dengan berbagai alasan sebesar 21, 5\% Hal ini mengindikasikan bahwa Komitmen karyawan belum maksimal sehingga dapat berpengaruh terhadap kinerjanya. Berdasarkan uraian tersebut di atas, maka penulis memandang betapa pentingnya faktor Kompensasi, Kompetensi dan Komitmen organisasi dalam peningkatan kinerja Karyawan. Penulis meyakini sungguhpun sudah ada judul penelitian yang sama tetapi karena adanya perbedaan baik obyek dan waktu penelitiannya, maka hal itulah yang mendorong penulis tertarik untuk melakukan penelitian tentang "Pengaruh Kompensasi, Kompetensi Dan Komitmen Organisasi Terhadap Kinerja Karyawan Sekretariat Jenderal Dewan Pimpinan Pusat Partai Golongan Karya".

\section{Landasan Teori}

Berikut ini adalah beberapa definisi kompensasi yang dikemukakan beberapa pakar. Menurut Hasibuan (2006: 118), "Kompensasi adalah semua pendapatan yang berbentuk uang, barang langsung atau tidak langsung yang diterima karyawan sebagai imbalan atas jasa yang diberikan kepada perusahaan". Pendapat Marwansyah (2010: 297), "Kompensasi adalah penghargaan atau imbalan langsung maupun tidak langsung, finansial maupun non finansial-- yang adil dan layak kepada karyawan, sebagai balasan atas kontribusi/jasanya terhadap pencapaian organisasi”. 
Menurut Palan (Noor Fuad dan Gofur Ahmad 2009) kompetensi didefinisikan sebagai deskripsi mengenai perilaku.Secara lebih terperinci deskripsi itu merujuk kepada karakteristik yang mendasari perilaku yang menggambarkan motif, karakteristik pribadi (ciri khas), konsep diri, nilai-nilai pengetahuan atau keahlian

Mowday (2002) mendefinisikan Komitmen Organisasi sebagai kekuatan relatif dari identifikasi individu dan keterlibatan dalam organisasi khusus, meliputi kepercayaan, dukungan terhadap tujuan dan nilai-nilai organisasi, dan keinginan yang kuat untuk menggunakan upaya yang sungguh-sungguh untuk kepentingan organisasi, dan kemauan yang kuat untuk memelihara keanggotaan dalam organisasi. Komitmen Organisasi menunjuk pada pengidentifikasian tujuan pegawai dengan tujuan organisasi, kemauan untuk mengerahkan segala upaya kepentingan organisasi dan keterikatan untuk tetap menjadi bagian organisasi (Mowday, Steers, Porter, 2007).

Menurut Johnson Dongoran, (2001:68) menegaskan, bahwa kinerja memainkan peran bagi peningkatan suatu kemajuan atau perubahan ke arah yang lebih baik yaitu terhadap pengukuran fakta-fakta yang akan menghasilkan data dan kemudian apabila data itu dianalisis secara tepat akan memberikan informasi yang akurat sehingga informasi itu akan berguna bagi peningkatan pengetahuan para pimpinan dalam pengambilan keputusan (Manajer).

\section{Metode}

Penelitian ini adalah penelitian deskriptif analitis, yaitu suatu rumusan masalah yang berkaitan dengan pertanyaan terhadap keberadaan variable mandiri baik hanya pada satu variabel atau lebih melalui hipotesis. Atau Deskriptif adalah penelitian yang membuat perbandingan dan bertujuan menganalisis hubungan antara variabel dengan suatu variabel yang mempengaruhi variabel lainnya (Sugiyono. 2015) Hubungan variabel dimaksud dapat digambarkan pada :

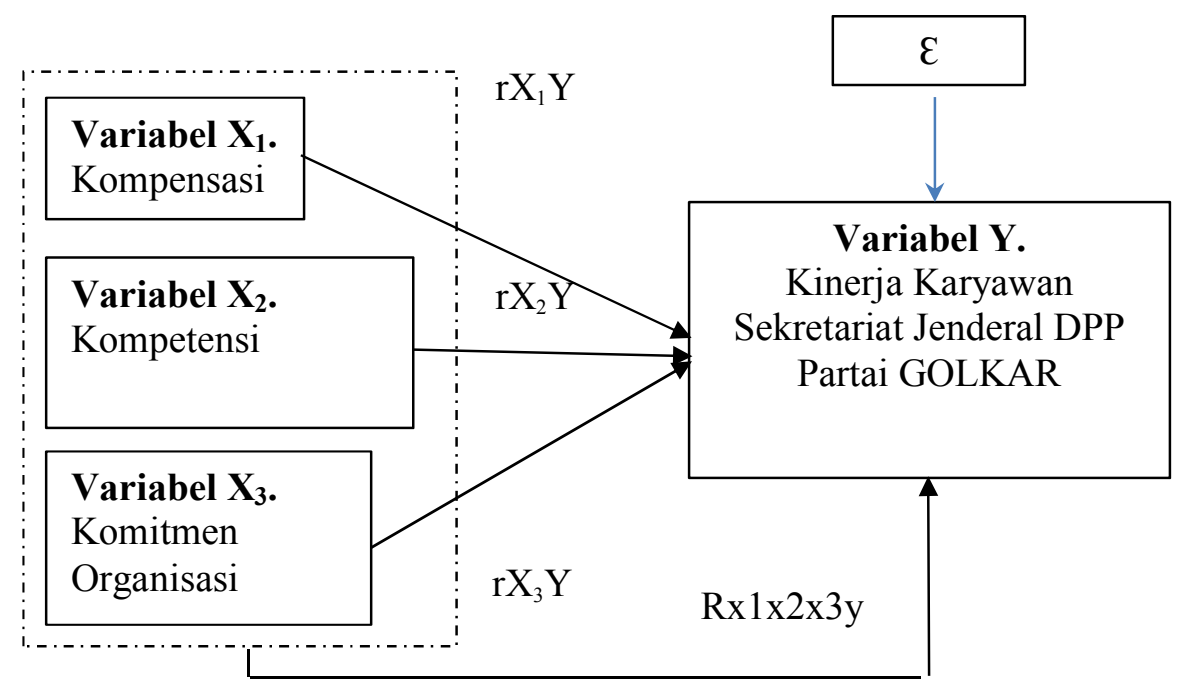

Gambar 1. Desain Penelitian 


\begin{tabular}{|c|c|c|}
\hline \multicolumn{2}{|c|}{ Keterangan : } & \multirow[b]{2}{*}{$\begin{array}{l}\text { Pengaruh variabel }\left(\mathrm{X}_{1}\right) \text { Kompensasi Terhadap variabel }(\mathrm{Y}) \text { Kinerja } \\
\text { karyawan Sekretariat Jenderal DPP Partai GOLKAR }\end{array}$} \\
\hline $\mathrm{rX}_{1} \mathrm{Y}$ & $=$ & \\
\hline $\mathrm{rX}_{2} \mathrm{Y}$ & $=$ & $\begin{array}{l}\text { Pengaruh variabel }\left(\mathrm{X}_{2}\right) \text { Kompetensi terhadap variabel }(\mathrm{Y}) \text { Kinerja } \\
\text { karyawan Sekretariat Jenderal DPP Partai GOLKAR }\end{array}$ \\
\hline $\mathrm{rX}_{3} \mathrm{Y}$ & $=$ & $\begin{array}{l}\text { Pengaruh variabel }\left(\mathrm{X}_{3))} \text { Komitmen Organisasi }\right. \\
\text { (Y) Kinerja karyawan Sekretariat Jenderal DP }\end{array}$ \\
\hline $\mathrm{Rx}_{123} \mathrm{Y}$ & $=$ & $\begin{array}{l}\text { Pengaruh variabel }\left(\mathrm{X}_{1}\right) \text { Kompensasi, variabel }\left(\mathrm{X}_{2}\right) \text { Kompetensi, dan } \\
\text { variabel }\left(\mathrm{X}_{3}\right) \text { Komitmen organisasi secara bersama-sama terhadap } \\
\text { variabel }(\mathrm{Y}) \text {, Kinerja Karyawan Sekretariat Jenderal DPP Partai } \\
\text { GOLKAR }\end{array}$ \\
\hline & & $\begin{array}{l}\text { Variabel lain yang berpengaruh terhadap kinerja tetapi tidak } \\
\text { diteliti. }\end{array}$ \\
\hline
\end{tabular}

\section{Hasil Dan Pembahasan}

Hasil pengolahan data dilakukan dengan menggunakan program SPSS yang akan dianalisis sebagai berikut:

Uji reliabilitas digunakan untuk mengukur suatu kuesioner yang merupakan indikator dari variabel atau konstruk. Suatu kuesioner dikatakan reliabel atau handal jika jawaban seseorang terhadap pertanyaan adalah konsisten atau stabil dari waktu ke waktu. Suatu konstruk atau variabel dikatakan reliabel jika memberikan nilai Cronbach Alpha $>0,6$.

Tabel 3. Ringkasan Uji Reliabilitas

\begin{tabular}{clcc}
\hline No. & \multicolumn{1}{c}{ Variabel } & Hasil Uji & Keterangan \\
\hline 1. & Kompensasi (X1) & 0,765 & Diterima / reliable \\
2. & Kompetensi (X2) & 0,763 & Diterima / reliable \\
3. & Komitmen Organisasi (X3) & 0,759 & Diterima / reliable \\
4. & Kinerja Karyawan (Y) & 0,761 & Diterima / reliable
\end{tabular}

Sumber : Data Primer Terolah dari SPSS 20

Uji validitas akan menguji masing-masing variabel yang digunakan dalam penelitian ini, dimana keseluruhan variabel penelitian memuat 60 pertanyaan yang harus dijawab oleh responden. Adapun kriteria yang digunakan dalam menentukan valid tidaknya pertanyaan yang digunakan dalam penelitian ini adalah sebagai berikut: tingkat kepercayaan $=95 \%(D=5 \%)$, derajat kebebasan $(\mathrm{df})=\mathrm{n}-2=92-2=90$, didapat $\mathrm{r}$ tabel $=0,2050$. Jika $\mathrm{r}$ hitung (untuk tiap butir dapat dilihat pada kolom Corrected Item - Total Correlation) lebih besar dari $\mathrm{r}$ tabel dan nilai $\mathrm{r}$ positif, maka butir pernyataan dikatakan valid. Kompensasi, Kompetensi dan Komitmen Organisasi berpengaruh secara simultan atau bersama-sama terhadap kinerja karyawan Variabel ketiga tersebut menunjukan bahwa seluruh item yang ada pada variabel tersebut adalah valid, karena nilai Sig dari masing-masing item adalah lebih kecil dari 0,05. Uji Asumsi Klasik. Untuk melakukan uji asumsi atas data primer ini, maka peneliti melakukan uji normalitas, uji homogenitas, uji multikolinearitas, dan uji heteroskedastisitas. Uji 
Normalitas. Model regresi yang baik adalah yang memiliki distribusi data normal atau mendekati normal.

Tabel 4. Uji Multikolinearitas

\begin{tabular}{|c|c|c|c|c|c|c|c|c|c|c|}
\hline \multicolumn{11}{|c|}{ Coefficients } \\
\hline \multirow[t]{2}{*}{ Model } & \multicolumn{2}{|c|}{$\begin{array}{l}\text { Unstandardized } \\
\text { Coefficients }\end{array}$} & \multirow{2}{*}{$\begin{array}{c}\begin{array}{c}\text { Standardized } \\
\text { Coefficients }\end{array} \\
\text { Beta }\end{array}$} & \multirow[t]{2}{*}{$\mathrm{T}$} & \multirow[t]{2}{*}{ Sig. } & \multicolumn{3}{|c|}{ Correlations } & \multicolumn{2}{|c|}{$\begin{array}{c}\text { Collinearity } \\
\text { Statistics }\end{array}$} \\
\hline & $\mathrm{B}$ & Std. Error & & & & $\begin{array}{l}\text { Zero- } \\
\text { order }\end{array}$ & Partial & Part & $\begin{array}{c}\text { Toleranc } \\
\mathrm{e}\end{array}$ & VIF \\
\hline (Constant) & 8.899 & 3.432 & & 2.593 & .011 & & & & & \\
\hline Kompensasi & .105 & .114 & .129 & .922 & .359 & .716 & .098 & .051 & .158 & 6.340 \\
\hline Kompetensi & .779 & .139 & .786 & 5.622 & .000 & .851 & .514 & .312 & .157 & 6.355 \\
\hline $\begin{array}{l}\text { Komitmen } \\
\text { Organisasi }\end{array}$ & -.040 & .204 & -.041 & -.196 & .845 & .795 & -.021 & -.011 & .071 & 14.083 \\
\hline
\end{tabular}

Sumber : Data Primer Terolah dari SPSS 20

Berdasarkan data tabel 4 diatas dapat dilihat bahwa nilai VIF (Variance Inflation Factor) untuk variabel kompensasi $\left(\mathrm{X}_{1}\right)$ adalah sebesar 6,340 untuk variabel kompetensi $\left(\mathrm{X}_{2}\right)$ sebesar 6,355 untuk variabel komitmen organisasi $\left(\mathrm{X}_{3}\right)$ sebesar 14,083.Pada uraian tersebut, terlihat bahwa pada kolom VIF semua variabel bebas mempunyai nilai lebih kecil dari 10. Begitu juga pada kolom tolerance, untuk variabel $\left(\mathrm{X}_{1}\right)$ mempunyai nilai tolerance sebesar 0.158 , untuk variabel $\left(\mathrm{X}_{2}\right)$ mempunyai nilai sebesar 0.157 , dan variabel $\left(\mathrm{X}_{3}\right)$ mempunyai nilai tolerance sebesar 0,071. Dengan demikian, berdasarkan hasil analisa yang disajikan pada uraian diatas dapat disimpulkan bahwa antar semua variabel bebas dalam penelitian ini tidak ada yang berkorelasi secara sempurna atau tidak terjadi multikolinearitas.

uji heteroskedastisitas, yaitu untuk mendeteksi terjadinya heteroskedastisitas atau homoskedastisitas dan dapat digunakan metode Scatterplots. Dasar analisis dari heteroskedastisitas adalah :

1. Jika ada pola tertentu, seperti titik-titik yang ada membentuk pola tertentu yang teratur (bergelombang, melebar kemudian menyempit), maka mengindikasikan terjadi heteroskedastisitas.

2. Jika tidak ada pola yang jelas, serta titik-titik menyebar di atas dan di bawah angka 0 pada sumbu Y, maka tidak terjadi heteroskedastisitas. Hasil metode Scatterplots dari penelitian ini dapat dilihat pada gambar 2 berikut :

Gambar 2. Hasil Uji Heteroskedastisitas

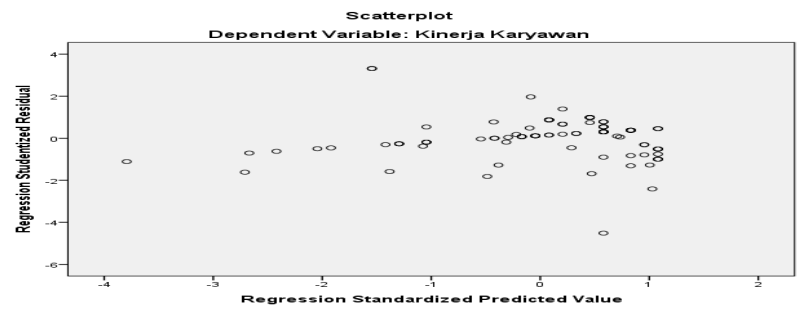

Sumber : Data Primer Terolah dari SPSS 20 
Pada gambar 2 diatas menunjukan hasil pengujian dengan menggunakan metode scatterplot, hasil uji ini menunjukan bahwa titik-titik menyebar secara acak serta tersebar baik di atas maupun di bawah angka 0 pada sumbu Y, maka dapat disimpulkan dalam model regresi ini kedua persamaan tersebut tidak terjadi masalah heteroskedastisitas.

Analisis regresi linear berganda dimaksudkan untuk menguji sejauh mana arah dan pengaruh variabel-variabel independen terhadap variabel dependen.Variabel independen dalam penelitian ini adalah kompensasi $\left(\mathrm{X}_{1}\right)$, kompetensi $\left(\mathrm{X}_{2}\right)$, komitmen organisasi $\left(\mathrm{X}_{3}\right)$, dan Variabel dependen $(\mathrm{Y})$ adalah kinerja karyawan. Uji pengaruh simultan digunakan untuk mengetahui apakah variabel independen secara bersama-sama atau simultan mempengaruhi variabel dependen.Uji ini dapat dilihat pada nilai $\mathrm{F}$ test.

Tabel 5. Uji Signifikan Simultan ( Uji Anova)

\begin{tabular}{|l|l|l|r|r|r|r|}
\hline \multicolumn{7}{|c|}{ ANOVA $^{\text {a }}$} \\
\hline \multicolumn{2}{|l|}{ Model } & $\begin{array}{c}\text { Sum of } \\
\text { Squares }\end{array}$ & \multicolumn{1}{c|}{ df } & $\begin{array}{c}\text { Mean } \\
\text { Square }\end{array}$ & F & Sig. \\
\hline \multirow{3}{*}{1} & Regression & 4148.030 & 3 & 1382.677 & 78.949 & $.000^{b}$ \\
\cline { 2 - 7 }$y$ & Residual & 1541.187 & 88 & 17.513 & & \\
\cline { 2 - 8 } & Total & 5689.217 & 91 & & & \\
\hline
\end{tabular}

Sumber : Data Primer Terolah dari SPSS 20

Dari tabel diatas dapat nilai $\mathrm{F}$ hitung sebesar 20,712 dengan probabilitas 0,000 , karena probabilitas jauh lebih kecil dari 0,05 maka dapat dikatakan bahwa variabel $X_{1}, X_{2}$ dan $X_{3}$ terhadap variabel $Y$ berpengaruh secara bersama-sama atau dengan kata lain variabel kompensasi, kompetensi dan komitmen organisasi berpengaruh secara simultan atau bersama-sama terhadap kinerja karyawan.

\section{Kesimpulan}

1. Terbukti bahwa terdapat pengaruh Kompensasi terhadap Kinerja Karyawan berdasarkan Adjusted R Square adalah 0,512 atau 51,2\%, sedangkan yang $48,8 \%$ dipengaruhi oleh faktor lain yang tidak masuk dalam variabel penelitian ini

2. Terbukti bahwa terdapat pengaruh Kompetensi terhadap Kinerja Karyawan berdasarkan Adjusted R Square adalah 0,725 atau 72,5\%, sedangkan yang $27,5 \%$ dipengaruhi oleh faktor lain yang tidak masuk dalam variabel penelitian ini

3. Terbukti bahwa terdapat pengaruh Komitmen Organisasi terhadap Kinerja Karyawan berdasarkan Adjusted R Square adalah 0,631 atau 63,1\%, sedangkan yang $38,9 \%$ dipengaruhi oleh faktor lain yang tidak masuk dalam variabel penelitian ini

4. Terbukti bahwa terdapat pengaruh secara simultan berdasarkan Adjusted R Square Kompensasi, Kompetensi dan Komitmen Organisasi terhadap Kinerja Karyawan adalah 0,720 atau $72 \%$, sedangkan yang $28 \%$ dipengaruhi oleh faktor lain yang tidak masuk dalam variabel penelitian ini 


\section{Daftar Pustaka}

A.A.Anwar Prabu Mangkunegara. 2011. Manajemen Sumber Daya Manusia Perusahaan. PT.Remaja Rosda Karya : Bandung.

Ali, Mustofa. 2015. Pengaruh Kompensasi. Kompetensi. dan Iklim Kerja Terhadap Kinerja Operator Tb. Building PT Gajah Tunggal Tbk. Plant A. Tesis pada MM UMT 2015 : Tangerang.

Arini, T. Soemohadiwidjojo. 2015. Panduan Praktis Menyusun KPI Key Performance Indicator. Raih Asa Sukses : Jakarta.

Arikunto, Suharsimi. 2003. Prosedur Penelitian Suatu Pendekatan Praktek Rineka Cipta : Jakarta.

Bernardin, H. John. \& Joyce E.A Russel. 2003. Human resource management (An Experimental Approach International Edition. Mc.Graw Hill Inc : Singapore.

Dewan Pimpinan Pusat Partai Golkar. 2010. Keputusan Dewan Pimpinan Pusat Partai Golongan Karya Nomor KEP. 97/DPP/GOLKAR/VII/2010 Tentang Petunjuk Operasional Pembinaan karyawan Sekretariat Dewan Pimpinan Pusat Partai Golkar. Jakarta.

Dewan Pimpinan Pusat Partai Golkar. 2010. Keputusan Dewan Pimpinan Pusat Partai Golongan Karya Nomor KEP. 66/DPP/GOLKAR/V/2010 Tentang Struktur Organisasi dan Tata Kerja Sekretariat Dewan Pimpinan Pusat Partai Golkar. Jakarta.

Dwi Ari Wibawa. 2013. Kepemimpinan Transaksional dan Kepemimpinan Transformasional. Alumni Diklat Kepemimpinan III Angkatan 50. Berjuang dari Markas Besar Kampus Eksekutif "Muria" Badan Diklat Provinsi Jawa Tengah. Tanggal 13 Mei s/d 09 Juli 2013 : Semarang.

Dwi R. Hartanto dan Darmi Sih Astuti. 2012. Pengaruh Komunikasi. Kepemimpinan dan Budaya Organisasi terhadap Kinerja Karyawan Pada PDAM Kabupaten Demak. Students' Journal of Economic and Management. Universitas Stikubank (Unisbank) : Semarang.

Fuad, Mas'ud. 2004. Survai Diagnosis Organisasional. Badan Penerbit Universitas Diponegoro : Semarang.

George R. Terry. 2006. Prinsip-Prinsip Manajemen. Penerbit Bumi Aksara : Jakarta

Hartati dan Yasri. 2014. Pengaruh kepemimpinan. Kompensasi dan Iklim Organisasi Terhadap Motivasi Pegawai Dinas Sosial dan Tenaga Kerja Kota Padang Panjang Jurnal : Hartati dan Yasri 2014. Universitas Negeri Padang : Padang

Hasil Munas VIII Partai Golongan Karya Tahun. 2009. Sekretariat Jenderal DPP Partai Golkar : Jakarta

Husein, Umar. 2003. Metode Riset Bisnis Cetakan Pertama. Penerbit PT. Gramedia Pustaka Utama : Jakarta.

I Ketut R. Sudiarditha. 2013. Pengaruh Kompensasi dan Kompetensi terhadap komitmen serta dampaknya pada kinerja karyawan. (Suatu survei pada hotel bintang di daerah pengembangan Provinsi Bali). Jurnal Fakultas Ekonomi Universitas Negeri Jakarta Vol. XVII. No. 03, Oktober 2013.

Kadarisman. 2012. Manajemen Kompensasi. Penerbit : Rajawali Pers Raja Grafindo Grup 
Karyoto. 2016. Dasar-Dasar Manajemen - Teori. Definisi dan Konsep. Penerbit CV. Andi Offset : Yogyakarta.

Kreitner. Robert. 2014. Perilaku Organisasi (Organisational Behavior). Penerbit Salemba Empat : Jakarta.

Marwansyah. 2010. Manajemen sumber daya manusia. Alfabeta: Bandung.

Mathis Robert L, dan Jackson John H. 2006. Human Resource Management. alih bahasa. Salemba Empat: Jakarta.

Melizawati. 2015. Pengaruh komitmen organisasi terhadap kinerja karyawan (studi kasus

Pada PT. Indotirta Abadi di Gempol Pasuruan Jurnal Universitas Negeri Surabaya Fakultas Ekonomi Jurusan Prodi Akuntansi 2015.

Moeheriono. 2010. Pengukuran Kinerja Berbasis Kompetensi. Penerbit Ghalia Indonesia : Bogor.

Notoatmodjo, Soekidjo. 1998. Pengembangan Sumber Daya Manusia. Rineka Cipta : Jakarta.

........ 2009. Pengembangan Sumber Daya Manusia. Rineka Cipta : Jakarta.

Rachman, Nopan Nugraha. 2013. Pengaruh Diklat. Kompensasi. dan Motivasi berprestasi terhadap kinerja Pegawai Dinas Perindustrian dan Perdagangan Kota Tangerang Selatan. Tesis pada Prodi MM UMT Tangerang 2013 : Tangerang.

Rivai, Veithzal Zainal. 2015. Manajemen Sumber Daya Manusia untuk Perusahaan dari Teori ke Praktik. Cetakan Rajagrafindo Persada : Jakarta.

Robbins, Stephen P; Judge, Timothy A. 2008. Perilaku Organisasi. Edisi 12 Salemba Empat : Jakarta.

Sugiyono. 2002. Metode Penelitian Bisnis. Cetakan Pertama. Penerbit Alfabeta : Bandung.

........ 2015. Metode Penelitian Kuantitatif Kualitatif dan R\&D. Alfabeta : Bandung.

Sopiah. 2008. Perilaku Organisasi. Andi. : Yogyakarta.

Sutrisno Edy. 2009. Manajemen Sumber Daya Manusia. Kencana : Jakarta.

Terry, George dan Leslie W. Rue. 2010. Dasar Dasar Manajemen Cetakan kesebelas. PT Bumi Aksara : Jakarta.

Thamrin. 2015. Perencanaan Manajemen Sumber Daya Manusia. CV. Budi Utama : Yogyakarta.

Wibowo. 2011. Manajemen Kinerja. PT. Rajagrafindo Persada : Jakarta.

Widjaja, A \& Sianipar, Bernhard H. 2012. Pengaruh Motivasi. Kepuasan Kerja dan Disiplin terhadap kinerja Pegawai. Studi Kasus di Lapan. Sekolah Tinggi Manajemen Labora. Selasa 14 Februari 2012 : Jakarta.

Wijayanti, Irene Dianasari. 2008. Manajemen. Mitra Cendekia Press. Medan.

Wirawan. 2015. Manajemen Sumber Daya Manusia Indonesia Teori. Psikologi. Hukum Ketenagakerjaan. Aplikasi dan Penelitian : Aplikasi dalam Organisasi Bisnis. Pemerintahan dan Pendidikan. Cetakan Rajagrafindo Persada : Jakarta. 